\title{
Feasibility of Photofrin II as a Radiosensitizing Agent in Solid Tumors - Preliminary Results
} \author{
Ralf Wilkowski $^{\mathrm{a}}$ Anton Hofstetter ${ }^{\mathrm{d}}$ Eckhart Dühmke ${ }^{\mathrm{a}}$ \\ a Klinik und Poliklinik für Strahlentherapie und Radioonkologie, \\ b Institut für klinische Radiologie, Universität München, Germany \\ ${ }^{C}$ Dipartimento di Biologia, Università di Padova, Italy \\ d Laserlabor, Universität München, Germany
}

Moshe Schaffer ${ }^{a} \quad$ Birgit Ertl-Wagner ${ }^{b} \quad$ Pamela Manuela Schaffe

Key Words

Photofrin II · Radiosensitizer · lonizing irradiation

\section{Summary}

Background: Photofrin II has been demonstrated to serve as a specific and selective radiosensitizing agent in in vitro and in vivo tumor models. We aimed to investigate the feasibility of a clinical application of Photofrin II. Material and Methods: 12 patients were included in the study (7 unresectable solid tumors of the pelvic region, 3 malignant gliomas, 1 recurrent oropharyngeal cancer, 1 recurrent adenocarcinoma of the sphenoid sinus). The dose of ionizing irradiation was 30-50.4 Gy; a boost irradiation of $14 \mathrm{~Gy}$ was added for the pelvic region. All patients were intravenously injected with $1 \mathrm{mg} / \mathrm{kg}$ Photofrin II $24 \mathrm{~h}$ prior to the commencement of radiotherapy. Magnetic resonance imaging (MRI) controls and in some cases positron emission tomography (PET) were performed in short intervals. The mean follow-up was 12.9 months. Results: No major adverse events were noted. Minor adverse events consisted of mild diarrhea, nausea and skin reactions. A complete remission was observed in $4 / 12$ patients. A reduction in local tumor volume of $>45 \%$ was achieved in 4/12 patients. Stable disease was observed in 4/12 patients. 1 patient showed local disease progression after 5 months. Conclusion: The early follow-up results are encouraging regarding the feasibility of the application of Photofrin $\mathrm{II}$ as a radiosensitizing agent.

\author{
Schlüsselwörter \\ Photofrin II · Radiosensitizer · Ionisierende Strahlung
}

\section{Zusammenfassung}

Hintergrund: In der Vergangenheit wurde durch In-vitround In-vivo-Tumormodelle belegt, dass Photofrin II als spezifische, selektive radiosensibilisierende Substanz wirken kann. Unsere Pilotstudie sollte die mögliche klinische Anwendbarkeit von Photofrin II als strahlensensibilisierende Substanz evaluieren. Patienten und Methoden: In die Studie wurden 12 Patienten eingeschlossen (7 inoperable Tumoren der Beckenregion, 3 maligne Gliome, 1 Rezidiv eines Oropharynxkarzinoms und 1 Rezidiv eines Adenokarzinoms der Keilbeinhöhle). Die Dosis der ionisierenden Bestrahlung betrug 30-50,4 Gy; für die Beckenregion wurde eine Boostbestrahlung von $14 \mathrm{~Gy}$ hinzugefügt. $24 \mathrm{~h}$ vor Beginn der Strahlentherapie wurde $1 \mathrm{mg} / \mathrm{ml}$ Photofrin II intravenös injiziert. MRT (Magnetresonanztomographie)-Kontrollen und zum Teil PET (Positronen Emissions Tomographie) wurden in kurzen Zeitabständen durchgeführt. Der durchschnittliche Beobachtungszeitraum betrug 12,9 Monate. Ergebnisse: Schwerwiegende Nebenwirkungen traten nicht auf. Es wurden nur geringfügige Nebenwirkungen wie leichte Diarrhö, Übelkeit und Hautreaktionen beobachtet. Eine komplette Remission trat bei 4/12 Patienten ein. Eine Reduktion des lokalen Tumorvolumens von $>45 \%$ wurde bei $4 / 12 \mathrm{~Pa}$ tienten erzielt. Ein stabiler Krankheitsverlauf lag bei $4 / 12$ Patienten vor. Bei einem Patienten kam es nach 5 Monaten zu einer lokalen Progression des Tumors. Schlussfolgerung: Die Ergebnisse der Nachkontrollen sind bezüglich einer klinischen Anwendbarkeit von Photofrin II als radiosensibilisierendem Agens ermutigend.

\begin{tabular}{ll}
\hline KARGER & ๑ 2006 S. Karger GmbH, Freiburg \\
Fax +497614520714 & Accessible online at: \\
$\begin{array}{l}\text { E-mail Information@Karger.de } \\
\text { www.karger.com }\end{array}$ & www.karger.com/onk \\
&
\end{tabular}




\section{Introduction}

The biological effects of radiation affect both neoplastic and normal tissues. The nature and extent of such effects, however, depend on selected biological parameters (e.g. oxygen supply, cell cycle) and can be modified by chemical agents, such as radiosensitizers, radioprotectors and chemotherapeutic agents [1]. This modification is important in order to achieve the maximum effect on tumor tissue, while at the same time minimizing the effect on normal tissue.

The selectivity of ionizing radiation, which is often relatively low for tumor as compared to normal tissue, can be improved by using computer-controlled irradiation protocols with different types of radiation. Moreover, the effect of radiation on tumor tissues can be optimized, as mentioned, by the addition of radiosensitizing agents, in order to achieve greater damage to the neoplastic tissue than would be expected from the additive effect of each modality. However, local failure is commonly observed, even for this combined therapeutic strategy, with local failure rates being as high as $60-80 \%$ at the time of death [2].

When using radiosensitizing agents, 2 main parameters must always be considered - the probability of local tumor control (corresponding to the therapeutic ratio) and the probability of complications. Most of the presently known and routinely used radiosensitizing agents have a poor selectivity and are not tumor-specific. The use of these compounds may also result in severe side effects due to their inherent toxicity [2].

During the 1980s, photodynamic therapy (PDT) began to emerge as a promising alternative for the treatment of early and localized tumors in which adequate local surgery is difficult, such as multifocal bladder cancer [3]. The technique involves the topical or systemic administration of a photosensitizing agent which is preferentially accumulated or retained by the tumor tissue, followed by illumination of the neoplastic area with light wavelengths specifically absorbed by the photosensitizer [4-5]. In this context, porphyrins and their analogues are most frequently used as photosensitizers. Their tetrapyrrolic macrocycle exhibits absorption bands in the red region of the visible spectrum $(600-800 \mathrm{~nm})$, which is endowed with a particularly high penetration power into human tissue [6]. At present, the main photosensitizer in clinical use for PDT treatments is Photofrin II ${ }^{\circledR}$ (Axan, Mont-Saint-Hilaire, Canada), a complex mixture of porphyrins produced through acid treatment of hematoporphyrin derivative (HpD) [7]. Photofrin II has recently been approved as a photosensitizing agent in the clinical treatment of selected solid tumors [3-5].

The preferential affinity displayed by Photofrin for tumors as compared to most normal tissues was the driving force in prompting studies aimed at investigating the possible use of porhyrins as tumor-sensitizers during radiotherapy. Specifically, the use of Photofrin as a radiosensitizer would be advantageous, since a single chemical agent could be injected and in-
Table 1. Patient population treated with Photofrin II as a radiosensitizer

\begin{tabular}{|c|c|c|c|}
\hline \multirow{2}{*}{$\begin{array}{l}\text { Patients, } \\
\mathrm{n}\end{array}$} & \multicolumn{2}{|l|}{ Sex } & \multirow[t]{2}{*}{ Diagnosis } \\
\hline & Male & Female & \\
\hline 3 & 2 & 1 & bladder carcinoma \\
\hline 1 & 1 & - & recurrent bladder carcinoma \\
\hline 1 & - & 1 & cervical cancer, FIGO IV \\
\hline 2 & - & 2 & pelvic sarcoma \\
\hline 3 & 2 & 1 & astrocytoma, WHO grade III \\
\hline 1 & 1 & - & recurrent oropharyngeal carcinoma \\
\hline 1 & 1 & - & $\begin{array}{l}\text { recurrent adenocarcinoma of the } \\
\text { sphenoid sinus }\end{array}$ \\
\hline
\end{tabular}

Table 2. Side effects

\begin{tabular}{lllll}
\hline \multirow{2}{*}{ Side effects } & \multicolumn{2}{l}{ Patients, $\mathrm{n}$} & & \\
\cline { 2 - 5 } & WHO I & WHO II & WHO III & WHO IV \\
\hline Skin & 3 & - & - & - \\
Rectal bleeding & - & - & - & - \\
Diarrhea & 2 & 2 & - & - \\
Cystitis & 4 & - & - & - \\
Nausea & 3 & 1 & - & - \\
Vomiting & 2 & 1 & - & - \\
\hline
\end{tabular}

crease the sensitivity of tumor tissue to both ionizing and nonionizing radiation.

Several recently published studies on tissue cultures and on murine tumor models have demonstrated the in vitro and in vivo efficacy of Photofrin II as both a specific and a selective radiosensitizing agent [8-12]. These animal studies have assessed the efficacy of the radiosensitizing action in terms of tumor doubling time $(\Delta \mathrm{t})$, i.e. the time interval for the tumor volume to double as compared to the volume at the time of irradiation. The $\Delta \mathrm{t}$ value was found to be 6.2 days for non-irradiated cancer (control cases) and increased to 10.9 days in the group of mice exposed to a combination of ionizing radiation and Photofrin II. The mechanism of action of Photofrin II as a radiosensitizer is not clear [8-12]. The radiosensitizing process of Photofrin II may involve the oligomeric porphyrin constituents which are enriched in Photofrin [8-12]. More specifically, it may involve clusters of stacked tetrapyrrolic macrocycles along which any unpaired electrons generated via an interaction of Photofrin with $\mathrm{OH}$ and $\mathrm{O}_{2}$ radicals may readily delocalize along the tetrapyrrolic macrocycles, thereby stabilizing the porphyrin radical and allowing its diffusion over relatively large distances from the initial point of generation. In addition, Photofrin II may minimize the possible onset of repair processes which often limit the radio-induced cellular damage. Other observations already published in the 1950 s and 1960s by Schwartz and Cohen [13-15] and later by other groups [16] have demonstrated that $\mathrm{HpD}$ acts as a radiosensi- 
Table 3. Early clinical results after application of Photofrin II as a radiosensitizer

\begin{tabular}{|c|c|c|c|}
\hline $\begin{array}{l}\text { Patients, } \\
\mathrm{n}\end{array}$ & Diagnosis & $\begin{array}{l}\text { Follow-up, } \\
\text { months }\end{array}$ & Results \\
\hline 1 & cervical cancer, FIGO IV & 27 & complete remission; disease-free \\
\hline 2 & pelvic sarcoma & 28 & complete remission; disease-free \\
\hline 3 & recurrent astrocytoma, WHO III & 5 & tumor progression after 5 months, patient died \\
\hline 4 & bladder carcinoma & 12 & $\begin{array}{l}45 \% \text { reduction in tumor volume; then } \mathrm{R} 0 \\
\text { resection; patient died of distant metastases, } \\
\text { no local recurrence }\end{array}$ \\
\hline 5 & bladder carcinoma & 4 & $\begin{array}{l}\text { no change in tumor volume; patient died of } \\
\text { distant metastases }\end{array}$ \\
\hline 6 & bladder carcinoma & 4 & $\begin{array}{l}\text { in PET only marginal tumor vitality; patient died } \\
\text { of myocardial infarction }\end{array}$ \\
\hline 7 & local recurrence of bladder carcinoma & 11 & $\begin{array}{l}35-40 \% \text { reduction in tumor volume; patient } \\
\text { declined surgery; lost to follow-up after }\end{array}$ \\
\hline 8 & astrocytoma, WHO III & 15 & $\begin{array}{l}11 \text { months; during this time no tumor progression } \\
\text { no change in tumor volume; subsequently treated } \\
\text { with chemotherapy }\end{array}$ \\
\hline 9 & astrocytoma, WHO III & 14 & $\begin{array}{l}\text { no change in tumor volume; in FET-PET no } \\
\text { signs of tumor vitality; disease-free }\end{array}$ \\
\hline 10 & pelvic sarcoma & 16 & $\begin{array}{l}45 \% \text { tumor reduction; subsequently treated with } \\
\text { chemotherapy and hyperthermia }\end{array}$ \\
\hline 11 & $\begin{array}{l}\text { recurrent adenocarcinoma of the sphenoid } \\
\text { sinus }\end{array}$ & 4 & $\begin{array}{l}40 \% \text { reduction of volume; in FET-PET no signs } \\
\text { of tumor vitality; disease-free }\end{array}$ \\
\hline 12 & recurrent oropharyngeal carcinoma & 3 & no change in tumor volume \\
\hline
\end{tabular}

FET-PET $={ }^{18} \mathrm{~F}$-fluoroethyl-L-tyrosine positron emission tomography. tizing agent in the treatment of tumors. $\mathrm{HpD}$ is a highly heterogeneous chemical derivative of $\mathrm{Hp}$ of which Photofrin II represents a partially purified form [7].

The primary aim of this study was to evaluate the feasibility of a clinical application of Photofrin II as a radiosensitizer in various solid tumors. In addition, a preliminary evaluation of the potential efficacy of the substance was to be performed.

\section{Patients and Methods}

A feasibility study was performed to evaluate the feasibility of the application of Photofrin II as a radiosensitizer, to assess the toxicity of the combination of Photofrin II and ionizing radiation, and to then find the optimal dose of Photofrin II as a radiosensitizing agent. In addition, preliminary data on the potential efficacy of the substance were to be gathered. In this feasibility study, no dose escalation was performed.

After approval from the local Institutional Review Board, a combined treatment of irradiation and Photofrin II as a possible selective radiosensitizer was offered. All patients gave informed consent to this treatment, conforming to the guidelines of Good Clinical Practice. Patients were advised to avoid direct contact with light and to especially protect their eyes in the first days after therapy due to the known photosensitivity of porphyrins [3-5]. All patients received a specially equipped room which was completely shielded from sunlight and was equipped with lighting not stronger than $40 \mathrm{~W}$.

A total of 12 patients were included in the study ( 5 female, 7 male, mean age 53.6 years). 7 patients had unresectable solid tumors in the pelvic region ( 4 cases of bladder cancer, 2 pelvic sarcomas and 1 cervical can- cer), 3 had a malignant glioma (WHO grade III), 1 male patient had recurrent oropharyngeal cancer and another male patient a recurrent adenocarcinoma of the sphenoide sinus (table 1 ). In all 7 patients with pelvic tumors, concomitant administration of chemotherapy was contraindicated. 1 of the 3 patients with malignant glioma was suffering from a tumor recurrence.

The applied dose of ionizing irradiation ranged between 44.4 and 50.4 Gy; a boost irradiation with $14 \mathrm{~Gy}$ was added for the pelvic region. In the malignant glioma cases, the irradiation dose was $30 \mathrm{~Gy}$ in the patient with tumor recurrence, as this patient had undergone irradiation with $60 \mathrm{~Gy}$ in the past, and $40 \mathrm{~Gy}+20 \mathrm{~Gy}$ boost in the other patients. The patient with recurrent oropharyngeal carcinoma was treated with brachytherapy at a dose of $30 \mathrm{~Gy}$, while the patient with recurrent carcinoma of the sphenoid sinus was treated with external beam irradiation at a dose of $45 \mathrm{~Gy}$ plus a $14 \mathrm{~Gy}$ boost. All patients were intravenously injected with a single dose of $1 \mathrm{mg} / \mathrm{kg}$ Photofrin II $24 \mathrm{~h}$ prior to the commencement of radiation therapy. We chose to apply our boost irradiation at the time of peak Photofrin II concentrations in order to achieve the maximum effect on the tumor tissue. Pharmakokinetic studies of Photofrin II and past in vivo experiments $[9,11]$ have demonstrated the main therapeutic window of Photofrin II to be in the first week of application.

The relative serum levels of Photofrin II were evaluated prior to the initiation of therapy. Subsequently, daily Photofrin II levels were assessed. The methodology applied was a reversed-phase ion-pairing high performance liquid chromatography (HPLC) with fluorescence detection after solid-phase extraction using the pure drug substance of Photofrin for calibration [17]. Magnetic resonance imaging (MRI) with a standardized protocol was performed prior to the initiation of therapy, immediately after the conclusion of therapy, and every 2-3 months thereafter. In 5 patients, positron emission tomography (PET) was performed in addition after the conclusion of therapy. 


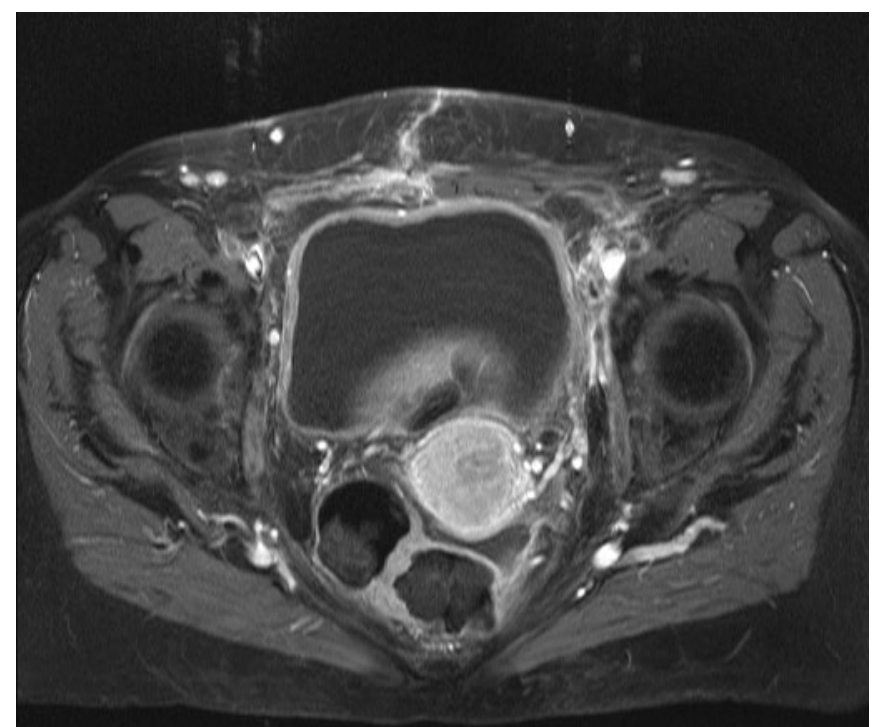

$\mathbf{A}$

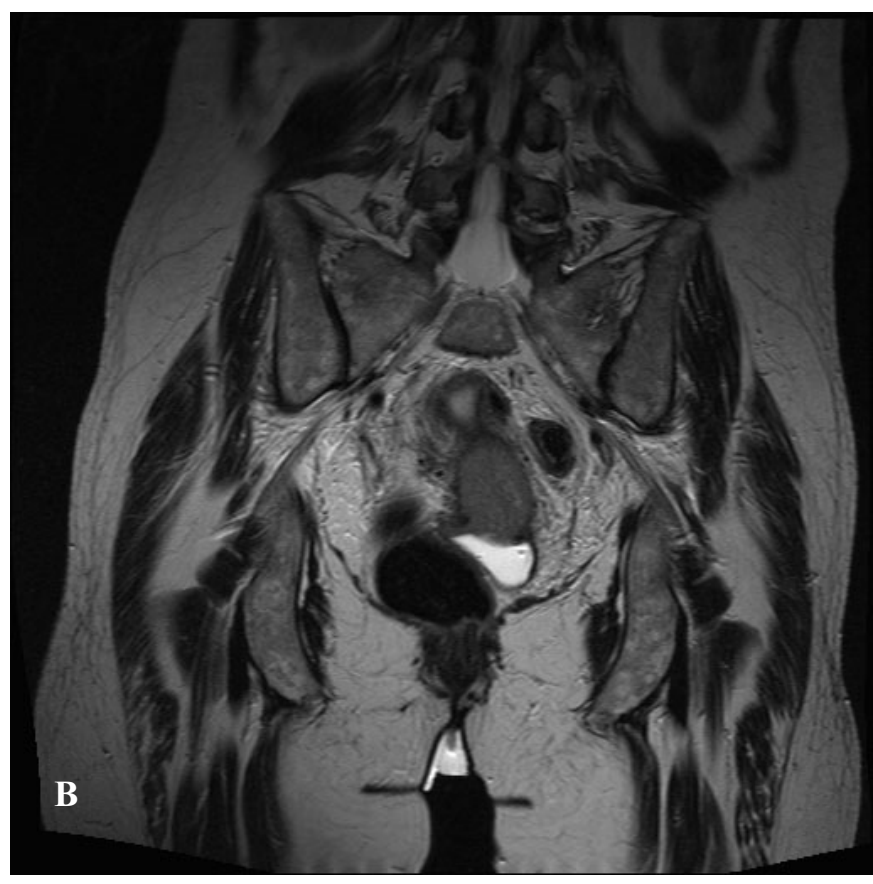

Fig. 1. A Axial $T 1$ - and B coronal $T 2$-weighted $M R$ images prior to therapy (after administration of paramagnetic contrast medium) demonstrate a large cervical carcinoma in a 60 -year-old patient involving almost two thirds of the uterus. The neoplastic tissue is relatively hyperintense as compared to the adjacent myometrium. Rectum and vagina were filled with a hydrophilic gel to optimize contrast.

\section{Results}

No major adverse events of the therapeutic regimen were noted in our patient population. Observed minor adverse events consisted of mild diarrhea, nausea and skin reactions (table 2). These minor adverse events of the therapeutic regi-
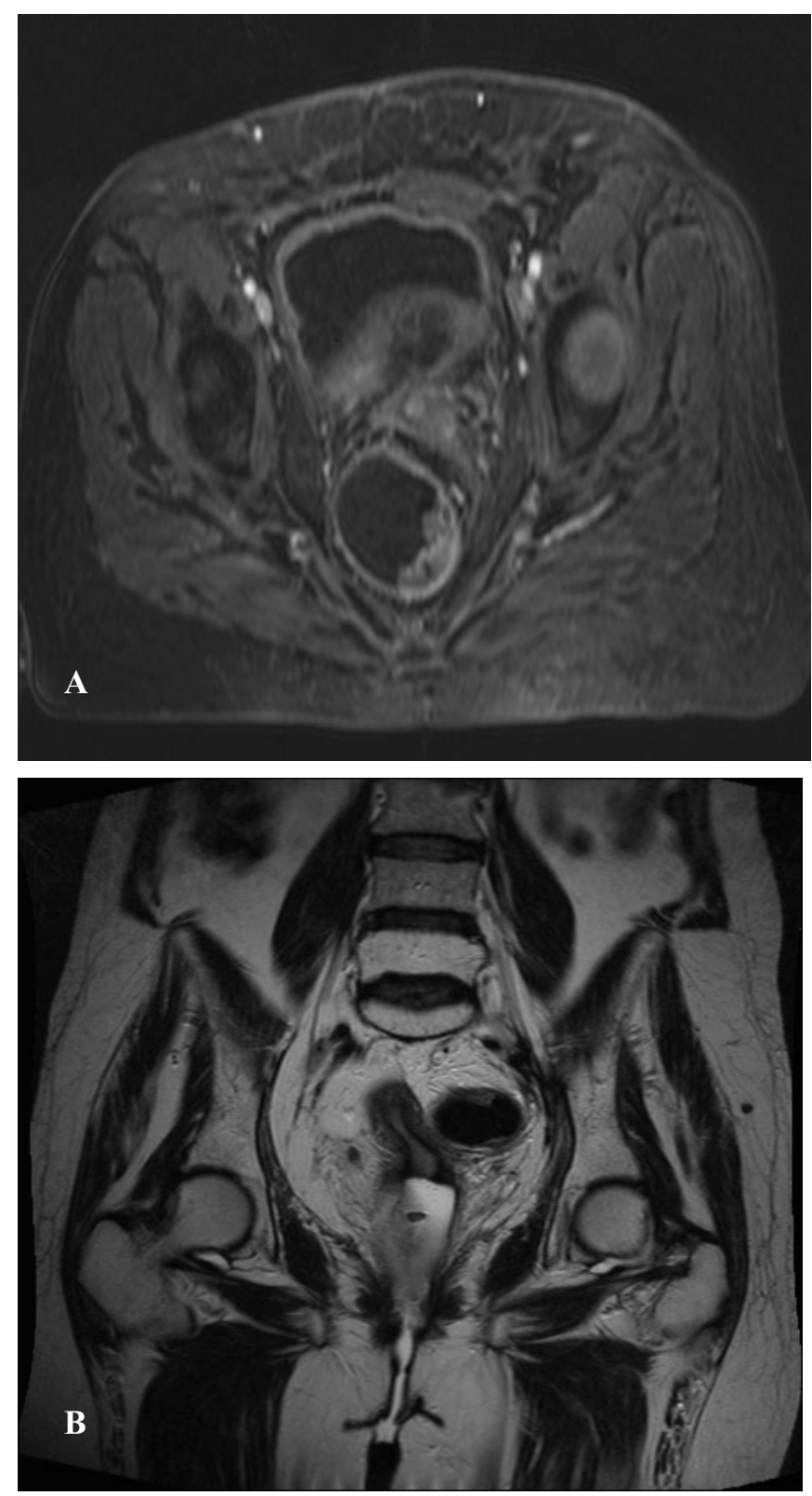

Fig. 2. A Axial T1- and B coronal T2-weighted MR images 12 months after the conclusion of therapy demonstrate an almost complete remission of the tumor. Only a very slight, small hyperintensity is present in the cervical region.

men did not significantly differ from the side effects routinely encountered with sole radiation therapy. Skin reactions, such as edema, erythema or other lesions, related to the photosensitizer (Photofrin II) were not seen or observed.

The relative serum level of Photofrin II peaked in the first 5-6 days after intravenous injection, followed by a subsequent steep decrease [17]. This timeframe correlates well with the therapeutic window.

Table 3 summarizes the follow-up data of our patient population with regard to tumor size as demonstrated by MRI and/or PET. The mean follow-up time was 12.9 months (range 4-32 
months). In the majority of patients, a significant reduction in tumor volume was observed. Complete clinical remission was found in 4/12 patients ( 1 pelvic sarcoma, 1 cervical cancer, 1 astrocytoma and 1 sphenoid adeno-carcinoma) (fig. 1, 2). A reduction in local tumor volume of $>45 \%$ was achieved in 4/12 patients; 1 of these patients was lost to follow-up after 12 months. Stable disease was observed in $4 / 12$ patients. 1 patient with an astrocytoma grade III had a local disease progression after 5 months. In addition, PET showed no tumor vitality in 4 of the 5 patients examined.

\section{Discussion}

The present work demonstrates the feasibility of a clinical application of Photofrin II as a radiosensitizing agent. The therapeutic dose range of Photofrin II as a photodynamic agent ranges between 1.0 and $2.5 \mathrm{mg} / \mathrm{kg}$ [18]. Since no literature is currently available on the dosage of Photofrin II as a radiosensitizing agent, we decided to treat with the lowest dose known to be therapeutic for PDT in order to avoid unknown complications, even though it had been demonstrated in the past that the presence of other porphyrins during irradiation does not enhance the local side effects of radiotherapy [19]. In this early phase of clinical testing, a dose escalation has not yet been performed. It will, however, be the aim of future studies to investigate a dose escalation of Photofrin II as a radiosensitizing agent.

As mentioned above, one of the limiting factors of the clinical application of Photofrin II may be its photosensitivity. The main strategy to avoid this complication consists in shielding the patients from sunlight and providing a specially equipped room with lighting at or below 40-60 W. The period during which shielding from light is required, differs from patient to patient and largely depends on liver function and general metabolism. Dougherty et al. [18] demonstrated that patients having received a relatively low dose $(1 \mathrm{mg} / \mathrm{kg})$ displayed a longer period of skin sensitivity than patients having received a dose of $2.5 \mathrm{mg} / \mathrm{kg}$. Moreover, when Shikowitz et al. [20] treated patients with PDT at the high dose of $4.5 \mathrm{mg} / \mathrm{kg}$ Photofrin II, the observed skin sensitivity was not increased in comparison to lower doses. We generally protected our patients from sunlight and light above $40 \mathrm{~W}$ for about 30 days depending on the Photofrin II serum levels in the HLPC. In our study population, we observed only minor skin reactions.
No major adverse events, specifically no major skin reactions, were found.

The therapeutic concentration of Photofrin in the tumor tissue was demonstrated to be reached between 24 and $72 \mathrm{~h}$ after injection [3-6, 21, 22]. This correlates well with the serum Photofrin II levels in our patient population as measured by a reversed-phase ion-pairing HPLC with fluorescence detection after solid-phase extraction using the pure drug substance of Photofrin for calibration. We chose to apply our boost irradiation at the time of peak Photofrin II concentrations in order to achieve the maximum effect on the tumor tissue.

In the past, the radiosensitizing effect of Photofrin II has been demonstrated in vitro and in animal models. The radiosensitizing effect was shown even in tumor models known to be highly radioresistant, such as glioblastoma and bladder carcinoma [12]. Photofrin alone caused no appreciable tumor response even at concentrations that yielded a marked radiosensitizing effect in the experimental setting. The combined action of Photofrin and ionizing radiation seems to be a saturable process $[8,9]$. Animal experiments have demonstrated the radiosensitizing activity of Photofrin II under optimal conditions to approach a factor of $3[8,9]$. Other commercially available porphyrins were shown not to act as radiosensitizers but only as photosensitizers during PDT $[9,10]$. An exception is represented by Gd-Tex that has been demonstrated to act as a radiation sensitizer both in vivo and in vitro [23, 24] However, some controversy remains regarding its efficacy [25]. Synthetic metallo-porphyrins have also shown a radiosensitizing effect [26]. The mechanism by which Photofrin II acts as a radiosensitizer is not yet completely understood. Regardless of its mechanism of action, however, past in vitro and animal studies and our current early clinical experiences appear promising.

Our study has several limitations that need to be taken into account when interpreting the data. First, our patient population is relatively small and heterogeneous in regard to the type of tumor. Second, the follow-up times are still limited with a mean follow-up time of 12.9 months. Moreover, the study design of this phase I study is inherently without randomization or a control group, thus limiting interpretations regarding the efficacy of the therapeutic regimen. However, in this current study, we primarily focused on the feasibility of the clinical use of Photofrin II as a radiosensitizer and its potential toxicity. As the results appear encouraging, further studies, including dose escalation studies, and eventually larger, randomized, multicenter studies are warranted

\section{References}

1 McBride WH, Withers HR: Biologic basis of radiation therapy; in Perez CA, Brady LW (eds): Principles and Practice of Radiation Oncology. Philadelphia, Lippincott Williams and Wilkins, 2004, pp. 96-136.
2 Wasserman TH, Chapman JD: Radiation response modulation, part A: chemical sensitizers and protectors. In: Perez CA Brady LW (eds): Principles and Practice of Radiation Oncology. Philadelphia, Lippincott Williams and Wilkins, 2004, pp. 663-679.
3 Stewart F, Baas P, Star W: What does photodynamic therapy have to offer radiation oncologists (or their cancer patients)? Radiother Oncol 1998;48: 233-248.

4 McDonald IJ, Dougherty TJ: Basic principles of photodynamic therapy. J Porphyrins Phthalocyanines 2001;5:105-129. 
5 Schmidt-Erfurth U, Miller JW, Sickenberg M: Photodynamic therapy for choroidal neurovascularization in a phase II study. Assoc Res Vision Ophthalmology 1997;38:74-75.

6 Foote CS: Definition of type I and type II photosensitized oxidation. Photochem Photobiol 1991;54: 659.

7 Byrne CJ, Marshallsay LV, Ward AD: The composition of Photofrin II. J Photochem Photobiol B 1990;6:13-27.

8 Schaffer M, Schaffer PM, Corti L, Sotti G, Hofstetter A, Jori G, Dühmke E Photofrin II as an efficient radiosensitizing agent in an experimental tumor. Onkologie 2001;24:482-485.

9 Schaffer M, Schaffer PM, Corti L, Gardiman M, Sotti G, Hofstetter A, Jori G, Dühmke E: Photofrin as a specific radiosensitizing agent for tumors: studies in comparison to other porphyrins, in an experimental in vivo model. J Photochem Photobiol B 2002;66:157-164.

10 Schaffer M, Schaffer PM, Jori G, Corti L, Sotti G, Hofstetter A, Dühmke E: Radiation therapy combined with photofrin or 5-ALA: effect on Lewis sarcoma tumor lines implanted in mice. Preliminary results. Tumori 2002;88:407-410.

11 Schaffer M, Schaffer PM, Hofstetter A, Duhmke E, Jori G: On the double role of photofrin as a photo- and a radio-sensitising agent: a possible new combination therapy for tumours. Photochem Photobiol Sci 2002;1:438-439.

12 Kulka U, Schaffer M, Siefert A, Schaffer PM, Ölsner A, Hofstetter A, Kassab K, Dühmke E, Jori G: Photofrin as a radiosensitizer in an in vitro cell survival assay. Biochem Biophys Res Commun 2003;311:98-103.

13 Schwartz S: Porphyrins and porphyrin precursors in human and experimental porphyria. Fed Proc 1955;14:717-722.

14 Schwartz S, Absolon K, Vermund H: Some relationships of porphyrins, X-rays and tumors. University of Minnesota Medical Bulletin 1955;27:7-13.

15 Cohen L, Schwartz S: Modification of radiosensitivity by porphyrins. II. Transplanted rhabdomyosarcoma in mice. Cancer Res 1966;26: 1769-1773.

16 Kostron H, Swartz MR, Miller DC, Martuza RL: The interaction of hematoporphyrin derivative, light, and ionizing radiation in a rat glioma model. Cancer 1986;57:964-970.

17 Vogeser M, Schaffer M, Egeler E, Spöhrer U: Development of an HPLC method for monitoring of Photofrin II therapy. Clin Biochem 2005;38:73-78.

18 Dougherty TJ, Cooper MT, Mang TS: Cutaneous phototoxic occurrences in patients receiving Photofrin. Lasers Surg Med 1990;10:485-488.

19 Schaffer M, Schaffer PM, Panzer M, Wilkowski R, Duhmke E: Porphyrias associated with malignant tumors: results of treatment with ionizing irradiation. Onkologie 2001;24:170-172.

20 Shikowitz MJ, Abramson AL, Freeman K, Steinberg BM, Nouri M: Efficacy of DHE photodynamic therapy for respiratory papillomatosis: immediate and longterm results. Laryngoscope 1998;108: 962-967.

21 Gomer CJ, Ferrario A: Tissue distribution and photosensitizing properties of mono-L-aspartyl chlorin e6 in a mouse tumour model. Cancer Res 1990;50: 3985-3990.

22 Orenstein A, Kostenich G, Roitman L, Kopolovic Y, Ehrenberg B, Malik Z: A comparative study of tissue distribution and photodynamic therapy selectivity of chlorin e6, Photofrin II and ALA-induced protoporphyrin IX in a colon carcinoma model. Br J Cancer 1996;73:937-944.

23 Sessler JL, Miller RA: Texaphyrins: new drugs with diverse clinical applications in radiation and photodynamic therapy. Biochem Pharmacol 2000;59: 733-739.

24 Miller RA, Woodburn K, Fan Q, Renschler MF, Sessler JL, Koutcher JA: In vivo animal studies with gadolinium (III) texaphyrin as a radiation enhancer. Int J Radiat Oncol Biol Phys 1999;45: 981-989.

25 Bernhard EJ, Mitchell JB, Deen D, Cardell M, Rosenthal DI, Brown JM: Reevaluating gadolinium(III) texaphyrin as a radiosensitizing agent: Cancer Res 2000;60:86-91.

26 O'Hara JA, Douple EB, Abrams MJ, Picker DJ, Giandomenico CM, Vollano JF: Potentiation of radiation-induced cell kill by synthetic metalloporphyrins. Int J Radiat Oncol Biol Phys 1989;16: 1049-1052. 